\title{
AIAA 2002-3240 \\ A Wind Tunnel Model to Explore Unsteady Circulation Control for General Aviation Applications
}

Christopher M. Cagle Gregory S. Jones

NASA-Langley Research Center

22 $^{\text {nd }}$ AIAA Aerodynamic Measurement Technology and Ground Testing

\author{
Conference \\ 24-26 June 2002 \\ St Louis, Missouri
}

For permission to copy or to republish, contact the copyright owner named on the first page. For AIAA-held copyright, write to AIAA Permissions Department,

1801 Alexander Bell Drive, Suite 500, Reston, VA, 20191-4344. 


\title{
A WIND TUNNEL MODEL TO EXPLORE UNSTEADY CIRCULATION CONTROL FOR GENERAL AVIATION APPLICATIONS
}

\author{
Christopher M. Cagle*, Gregory S. Jones** \\ NASA-Langley Research Center \\ Hampton, VA 23681
}

\begin{abstract}
Circulation Control airfoils have been demonstrated to provide substantial improvements in lift over conventional airfoils. The General Aviation Circular Control model is an attempt to address some of the concerns of this technique. The primary focus is to substantially reduce the amount of air mass flow by implementing unsteady flow. This paper describes a wind tunnel model that implements unsteady circulation control by pulsing internal pneumatic valves and details some preliminary results from the first test entry.
\end{abstract}

\section{INTRODUCTION}

As part of the aircraft morphing program at NASALangley Research Center (LaRC), many unconventional concepts are being studied to provide aerodynamic lift and control. Some of the more promising techniques involve virtual aerodynamic shape change as opposed to a real mechanical shape change. This is typically performed by flowing internal air in such a way that the external flow is affected in a positive manner. One of these methods, termed "circulation control" uses the Coanda effect to produce high lift without flaps or other conventional mechanical high lift devices. The Coanda effect shown in figure 1 can be described by a 2-D wall bounded jet that exits from a slot tangential to a convex curved surface. The wall bounded jet flows along the surface and has the nature of a boundary layer near the wall but becomes that of a free jet at a larger distance from the wall. ${ }^{1}$ The degree of jet turning can be related to the slot height, surface radius, jet velocity, and the Coanda surface geometry. The result is that local airflow can be directed downward, and in some cases, even reversed, producing a large lift component.

Over a period of 65 years, circulation control techniques related to Coanda effects have been numerically and exp erimentally studied. Many of these studies have focused on simplifying high lift systems. The success of this technique would be

\footnotetext{
- MOdEL design ENGINEER
}

* RESEARCH ENGINEER

Copyrightg 2002 by the American Institule of Aeronautics and Astronautics, Inc. No copyright is asserted in the Uniled States under Tite 17, U.S. Code. The U.S Government has a royalty-free liconse to exercise all rights under the copyright cleimed herein for Governmental Purposes. All other rights are reserved by the copyright owner. realized if conventional trailing edge control and high lift devices were replaced by a pneumatic system such as the one being investigated by the GACC program ${ }^{2}$. This simplification would potentially reduce weight and aircraft part count.

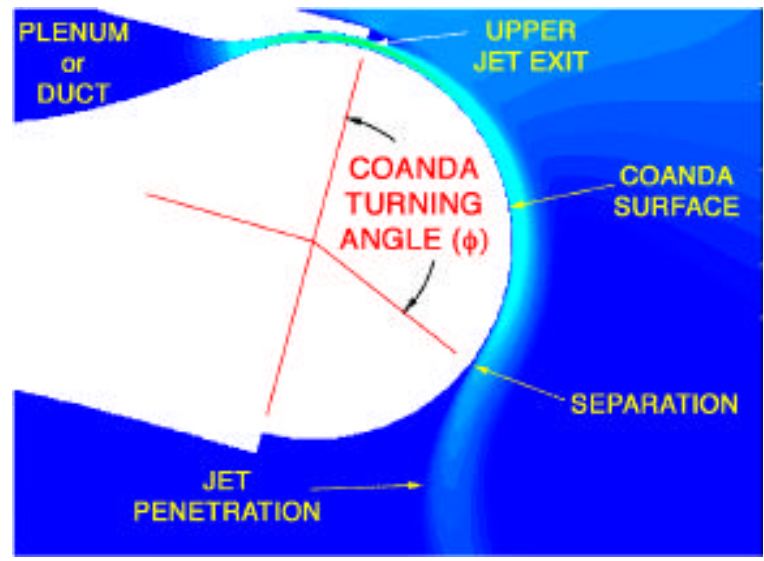

Figure 1 Coanda Effect

As with any new or alternate technology, there are several potential problems that need to be addressed.

- Where to get large volume of air for the internal flow

- Increased drag due to the bluff trailing edge

- Large nose down pitching moment

- Unknown noise effects.

This model, and follow-on efforts are intended to address these problems. This General Aviation Circular Control (GACC) model is a first generation 
LaRC effort to explore and validate the application of pulsed circulation control for general aviation configurations. The primary focus of this research is to significantly reduce the quantity of air needed by rapidly pulsing the jet flow. A secondary goal is to reduce the base drag created by the blunt trailing edge required of pneumatic systems. Future modifications to this model, or additional models will be used to address the other issues, such as noise and high-speed operations.

\section{TEST PARAMETERS}

The GACC model was tested in the LaRC Basic Aerodynamics Research Tunnel (BART), an open return atmospheric wind tunnel designed for low speed, high quality flow with modest operating costs. Air passes through a honeycomb, four antiturbulence screens, and an 11:1 contraction before entering the test section. The tunnel has a physical test section size of 28 " X 40" X 120". The maximum velocity at the test section entrance is 186 $\mathrm{ft} / \mathrm{s}$, which corresponds to a unit Reynolds Number ( $\mathrm{Re} / \mathrm{ft}$ ) of 1.13 million and a dynamic pressure of 40 $\mathrm{lb} / \mathrm{ft}^{2}$. The turbulence intensity varies from $0.03 \%$ at $50 \mathrm{ft} / \mathrm{s}$ to $0.09 \%$ at tunnel maximum velocity. The baseline GACC experiments were performed at a dynamic pressure of $10 \mathrm{lb} / \mathrm{ft}^{2}$.

The primary control parameter for this model is referred to as the momentum coefficient $(\mathrm{C} \mu)$, defined by

$$
\mathrm{C} \mu=\frac{\text { Thrust }}{\mathrm{qA}}=\frac{\dot{\mathrm{m}}\left(\mathrm{U}_{\mathrm{J}}\right)}{\mathrm{q}(\mathrm{S})(\mathrm{C})}
$$

where $m$ is the measured mass flow, $\mathrm{U}_{\mathrm{J}}$ is the velocity at the jet exit shown in figure $2, \mathrm{~S}$ is span, and $\mathrm{C}$ is chord. The jet exit velocity is based on the pressure ratio of the plenum and free stream static pressure.
$U_{J}=\sqrt{\frac{2 \gamma R\left(T_{\text {PLENUM }}\right)}{\gamma-1}\left(1-\left(\frac{P_{\infty}}{P_{\text {PLENUM }}}\right)^{\frac{\gamma-1}{\gamma}}\right.}$

where $\mathrm{R}$ is the gas constant for air and ? is ratio of specific heats ( 1.4 for air).

The test matrix focused on varying the physical test parameters that included external flow speed, internal steady pressure, trailing edge slot height, unsteady blowing air pressure, pulse frequency, duty cycle, and model angle of attack.

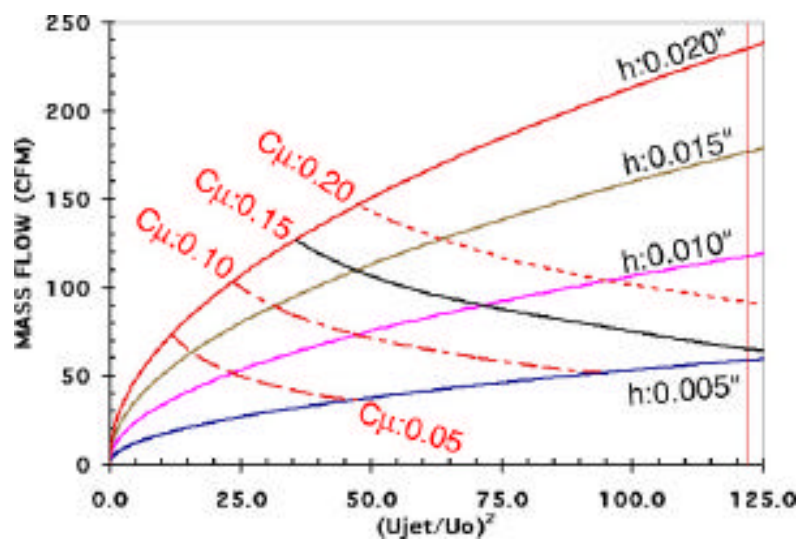

Figure 2 Mass flow requirements for specific momentum coefficients and different trailing edge configurations (ref dynamic pressure (q) of $10 \mathrm{lb} / \mathrm{ft}^{3}$ )

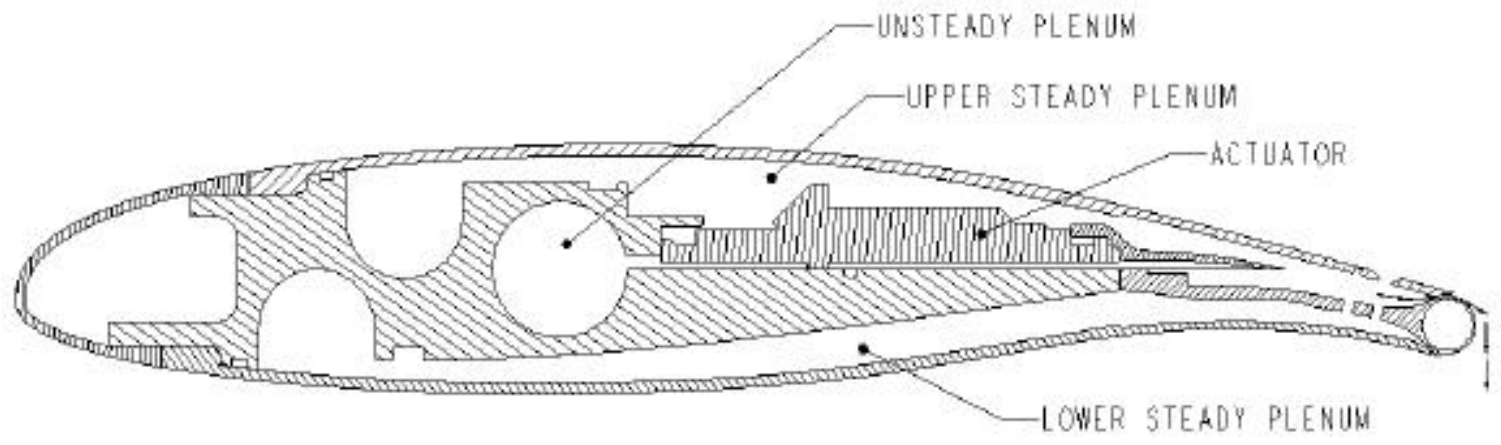

Figure 3 GACC Cross Section 


\section{GACC MODEL DEVELOPMENT}

\section{$\underline{\text { General Description }}$}

The GACC model is a 28" span, 9.4-inch chord two-dimensional GAW-1 airfoil modified by increasing the trailing edge thickness to accommodate a 3/8" trailing edge diameter (see figure 3). The air for the circulation control is introduced by means of thin slots tangential to the trailing edge diameter. Both upper and lower slots are supplied by continuous low pressure air. These separate air supplies can be operated independently, or in any combination. The pulsed air is provided by 20 independently controlled high-speed pneumatic valves capable of pulsed frequencies up to $200 \mathrm{~Hz}$. For initial testing, all actuator valves were operated concurrently. These valves are supplied by a plenum pressurized at a maximum of 200 psi. To minimize the attenuation of the flow pulses, the pneumatic valves are positioned as close to the trailing edge slot exit as possible. The goal for the unsteady flow is to achieve a step function at the slot exit.

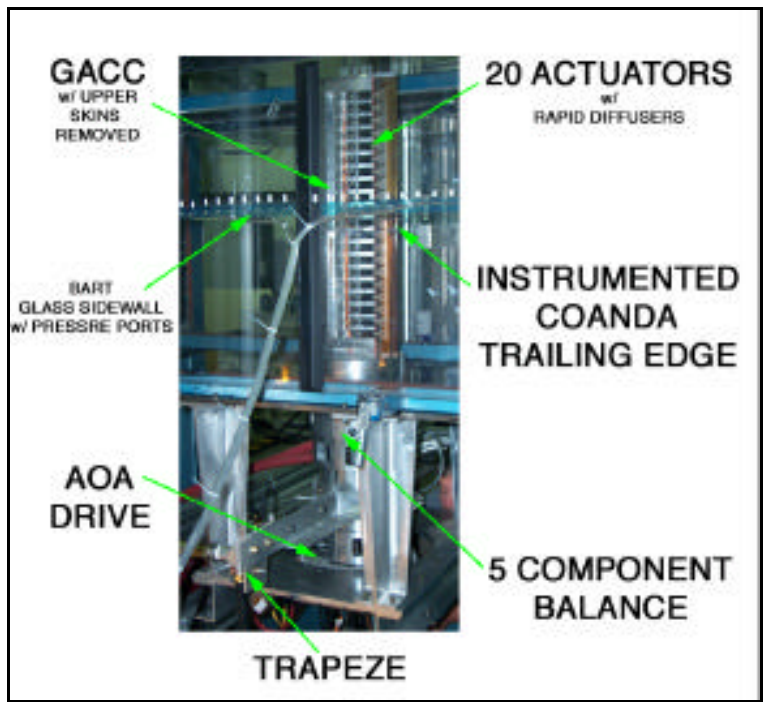

Figure 4 Photo of GACC model installed in BART

\section{Structural Details}

The model structure consists of an aluminum backbone mounted to a balance mounting plate (see appendix A). This backbone is the primary load carrying member as well as the source for the three separate pressure supplies. The plenum for the high pressure (200 psi maximum) pulsed air is fully contained within the backbone. This plenum is a simple bored cylinder with intersecting holes to feed each pneumatic actuator valve. The backbone was manufactured using Computer Numerically Controlled (CNC) milling to control airfoil contour. Channels were cut in the upper and lower surface that, in conjunction with the outer skins, form the flow path for the steady state flow. With everything contained inside the model (i.e. pneumatic valves, wiring for instrumentation and power), limited room is available to provide adequate air flow paths while maintaining structural integrity. As a result, the steady flow paths are what could be squeezed around the pneumatic valves. This results in a highly three-dimensional flow path that is not particularly clean, resulting in considerable pressure losses through the model.

The upper and lower outer skins are two dimensional contoured stainless steel plates, nominally .050 " thick, but thickened locally where needed for fasteners. Each skin was split in two pieces so that they could be manufactured using wire Electrical Discharge Machining (EDM). This produced a quality two-dimensional flow surface with minimal warpage in the thin section. They are simply screwed to the backbone, with each penetration sealed by an O-ring. These skins form one side of the pressure vessel for the low pressure steady state flow. There are certainly some leaks due to sheer number of penetrations, but during testing, they were not significant.

The leading edge is formed by a wire EDM contoured thin shell of aluminum, again split into two pieces for manufacturing convenience. This component is easily removed for access to instrumentation wiring and pressure tubing, and is not pressurized. There is no blowing yet in this area, but may be a consideration for future tests to address the pitching moment concern.

The trailing edge radius is formed as part of a component referred to as the aft spar. This component performs several functions. It provides a continuation of the flow path for the steady air. It supplies the trailing edge exterior flow geometry. It mounts the diffusers for the pulsed air. It also serves as a rigid platform to adjust the trailing edge slots. This highly three dimensional stainless steel component is built in three pieces, two long sections for the inboard and outboard areas, and a short, highly instrumented section roughly at mid span. It was manufactured using a combination of wire EDM and 3-axis CNC milling. The slot is varied between .005 " and .020 " by flexing the relatively thinner outer skins by means of opposing screws spaced at 1.25 " spanwise. This adjustment process is tedious, due to the number of screws and their small size, but proved to be able to provide very uniform slot adjustment. This method also corrects 
for any global warpage that may have occurred during fabrication of the skins and backbone.

\section{Actuator Performance}

The operational requirements for this model place a heavy demand on the actuator authority. To minimize pulse wave attenuation and unwanted 3-D effects, it was decided to place the valve system as close to the trailing edge as possible. This led to the development of a highspeed solenoid valve system using commercially available state-of-the-art pneumatic valves. The valve utilizes a piston that seats into a 0.10 " exit orifice, and is cycled from a fully open to fully closed position. These valves are controlled to produce a pneumatic pulse at duty cycles varying from $20-80 \%$ (tested). The output of the actuator shown in figure 5 is a jet of air ranging up to sonic speed with an exit diameter of approximately 1/10". The system uses 20 individually operated valves that produce a net air flow exceeding 100 standard cubic feet per minute (SCFM).

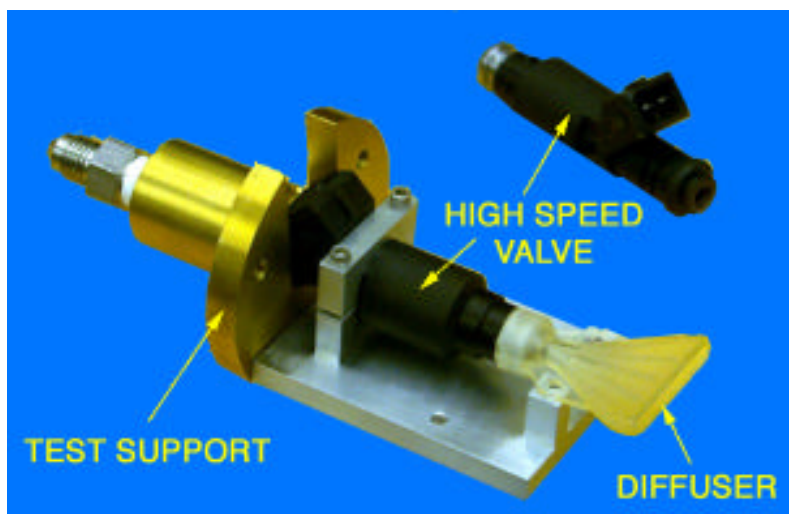

Figure 5 Photograph of GACC actuator with rapid diffuser

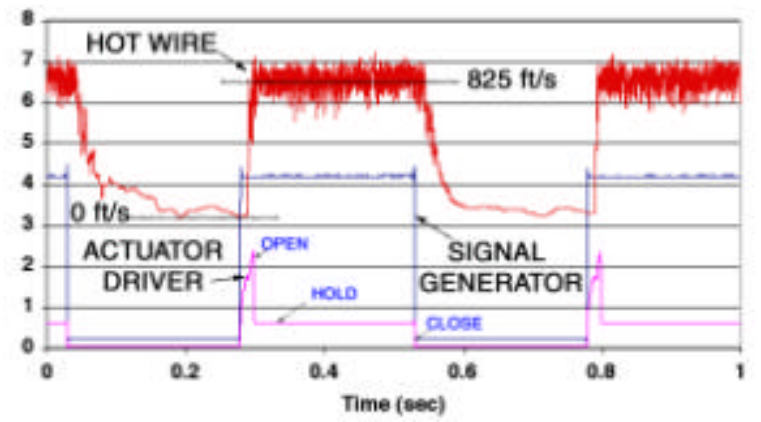

Figure 6 GACC performance for a single actuator (20 Hz, 200psia)

\section{Rapid Flow Diffuser Development}

One of the more significant challenges to providing a uniform slot exit velocity along the entire span for the unsteady blowing was the development of a rapid diffuser for the pulsed actuator. The actuator has an orifice diameter of approximately $1 / 10$ " that produces a circular jet that must be transitioned to a uniform thin sheet distributed along the span of the model. The difficulty in transitioning the high velocity actuator stream (up to sonic speed) to a uniform thin sheet of air (1.25" wide for the actuator spacing implemented) is related to minimizing the distortion of the pulsed jet at the exit plane. The pneumatic actuator was placed as far aft as possible to minimize flow attenuation. This left less than 2 inches of usable length for the flow expansion. A 10:1 diffuser was designed that met this length requirement and produced the necessary reduction in actuator air velocity to assure flow uniformity at the jet exit. This is an extremely aggressive design requirement for the small scales associated with the GACC model. Initial diffuser design was attempted using a 2-D Computational Fluid Dynamics (CFD) tool but was abandoned due to difficulties in code convergence that was related to the complex internal flow field that had a tendency of separating on one side of the diffuser.

After several largely unsuccessful attempts to run CFD solutions for one potential configuration, it was decided to try a trial and error approach based on empirical methods. LaRC has rapid prototyping capabilities through casting, high speed machining, and Stereolithography (SLA) processes that provided the rapid turnaround necess ary for such an approach. Using SLA to build these small parts, several variations could be fabricated overnight and tested the next day. The original plan was to optimize the internal shape using the SLA plastic parts with artificially thick walls so that strength would not be an issue. The external shape was largely defined by available space. After a suitable internal shape was found, then the shape with thinner wall sections would be cast in aluminum or other metal. The initial trial was made with three distinctly different internal flow paths (see figure 7). A test bed was setup in which a hot wire probe was traversed across the width of the diffuser exit to measure exit velocity.

Flow was not uniform across the width of the diffuser, but from all of the candidates, the 5 bullet configuration looked to have the best potential for getting an even flow distribution. Figure 8 shows a comparison of typical diffusers during the configuration development. 

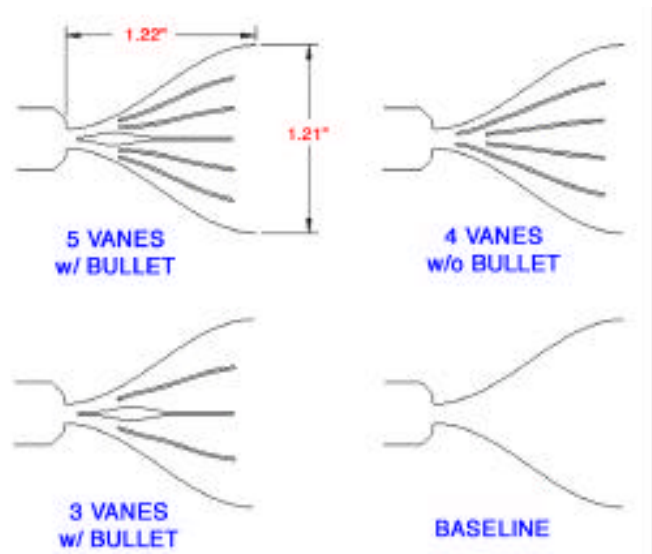

Figure 7 Examples of different rapid diffusers

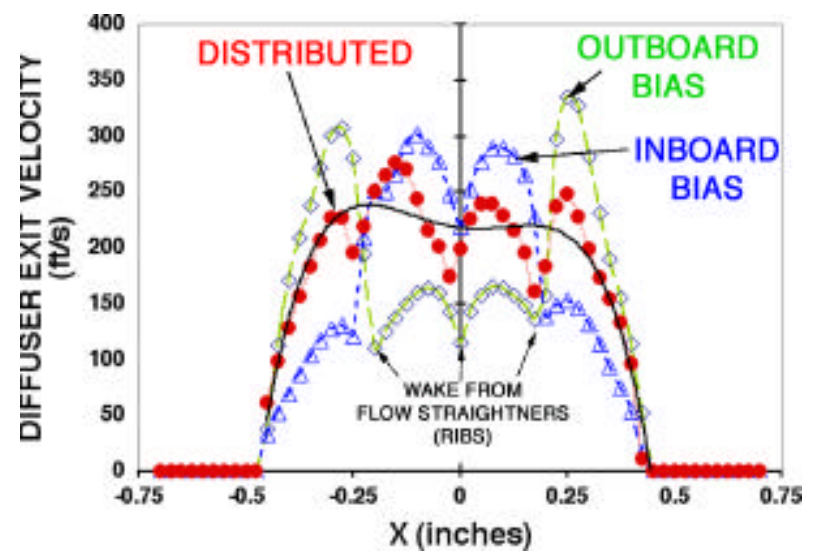

Figure 8 Comparison of steady exit velocity of different 3-Bullet rapid diffusers (diffuser area ratio 10:1)

Subsequent diffusers all used this basic configuration, but varied the widths of each chamber, and starting positions of the chamber walls. Blockage is an issue with this configuration, so the interior dividers were made as thin as practical. A minimum gage of .020 " was used. After a few of these diffusers were made in SLA plastic, it became clear that very subtle variations in geometry had dramatic effects on flow uniformity. It was a concern that any attempt to cast the shape in metal would have enough variation to void the tests on the plastic parts. Stress analysis was performed on the chosen configuration (in plastic) and it was determined to be structurally adequate. The rest of the test diffusers were made to net shape inside and outside. None of the plastic diffusers failed during testing. After about forty different variations were tested at realistic flow conditions (steady state), a down select was made to the 5-bullet configuration (see figure 9). Comparisons with flow tests conducted using pulsed air showed very little difference in diffuser performance. Steady state flow measurements were used to compare the many diffusers die to ease and speed of testing. The geometrical variations in the last set tested were on the order of .003", but it made very noticeable differences in flow quality. Twenty additional copies were made of the chosen configuration and used in the model.

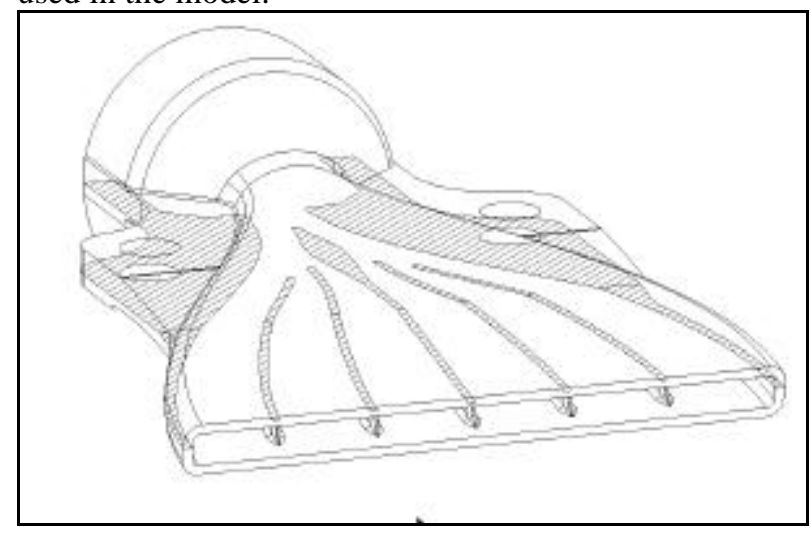

Figure 9 Stereolithography Diffuser ( 5 bullet)

\section{DESIGN AND MANUFACTURING}

This model was designed with the aid of the Pro/ENGINEER ${ }^{\circledR}$ Computer Aided Design (CAD) software. Appropriate analyses were performed using the Pro/MECHANICA ${ }^{\circledR}$ finite element software. These analyses included stress on the backbone due to aerodynamic loads and internal pressure. Also analyzed were the upper and lower skins to determine quantity and optimum spacing of fastener locations to minimize deflection due to internal pressure. Additionally, SLA plastic diffusers were analyzed for structural integrity.

Most of the manufacturing and all of the model fit and assembly were performed within the LaRC Fabrication Division. A second, smaller model was fabricated in -house of the same geometry, but with a 6 " chord. This model is capable of internal upper and lower trailing edge blowing, either steady state, or with externally supplied pulsing. Its primary purpose is for flow visualization. It was tested in a low speed water tunnel with hydrogen bubble generator to visualize streamlines (see figure 16).

\section{AIR SUPPLY SYSTEM}

The mass flow requirements for the GACC test matrix is based on limiting the momentum coefficients to less than 0.2 for slot heights less than 0.02 inches. Figure 2 shows that a maximum of 150 $\mathrm{ft}^{3} /$ min of steady air will be required to meet these conditions. The standard lab air supply systems found in most facilities are not adequate and do not meet the flow requirements. In addition to the low- 
pressure steady mass flow requirements of the upper and lower jets; the pulsed actuator system places an additional requirement of 200 psig to its inlet plenum. A custom air control system was designed and built for the GACC model, figure 10.

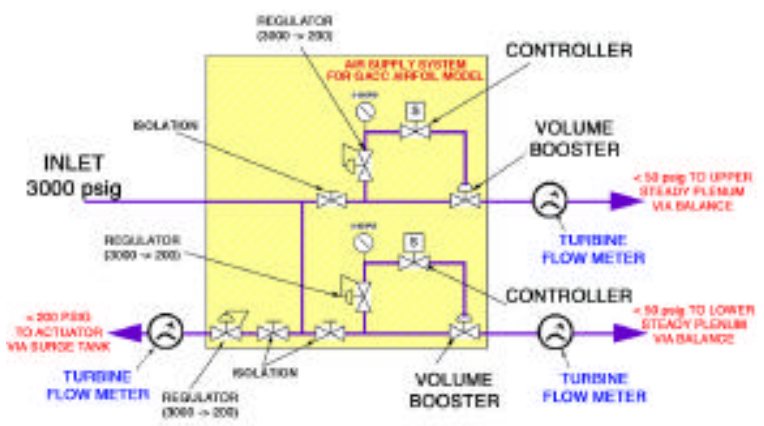

Figure 10 GACC air control system

For the risk reduction bench testing, a 3000 psig air source was provided by an existing auxiliary system that was available to the lab. However, a $50,000 \mathrm{ft}^{3}$ high-pressure air cylinder trailer was rented for the BART test series. Since the volume of air was limited, the data acquisition system was optimized for automated high-speed operations. During the wind tunnel testing, the air trailer was supplemented by available shop air for the lower pressure tests. A problem with using the high pressure air trailer was the daily weather changes (during December and January) and the JouleThompson cooling from the rapid expansion of the 1500 psi storage air to the maximum 200 psi test air. This caused the Coanda jet temperature to be less that the ambient wind tunnel temperature. Temperatures were therefore monitored and recorded for each plenum.

During the design of the test, it was not clear the best way to get the air past the balance without significantly affecting the balance measurements. There are traditional techniques requiring elaborate tubing trombones or pressure bellows. These were discarded in favor of a simpler trapeze type solution. Pressure is supplied to the base of the model through three 3/4-inch I.D. flexible hoses. These are hung vertically from the base of the model forming a trapeze. A short length of steel pipe with $90^{\circ}$ bends at each end turns the hose back up where it is firmly grounded to the non-metric side of the model support hardware (see figures 11,12). It is assumed that the flexibility of the hose will minimize any additional stiffness affecting the balance, and that the weight of the steel pipe at the bottom of the loop provides a stabilizing influence so that the hose has minimal movement due to pressurization.

\section{INSTRUMENTATION}

Balance

The GACC model was mounted on a 5component external strain gage balance that was

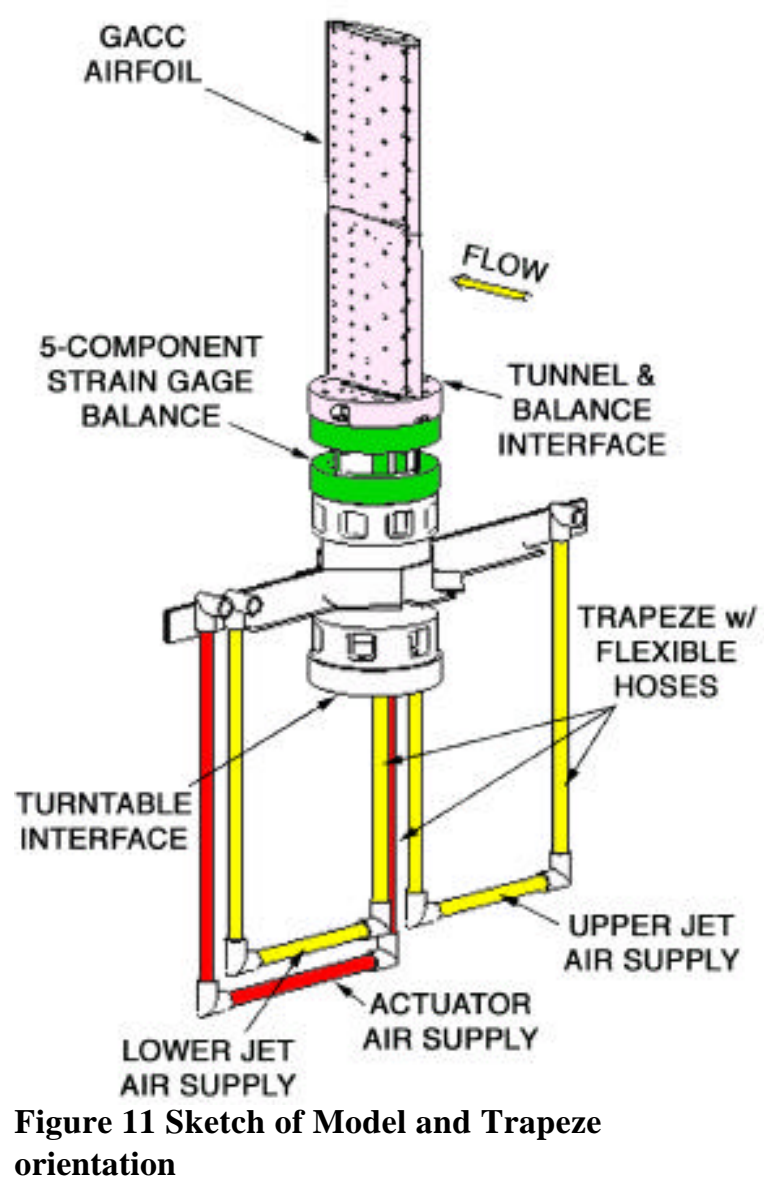

custom designed and fabricated for this test. Since the model was mounted vertically, the gravity direction was ignored. This side force measurement was eliminated due to the high forces generated by the air delivery system. Given that the model was mounted as a semi-span wing, the rolling moment is high relative to other forces. The design of the balance was not trivial. Having large differences in the measurement requirements complicated the balance design.

The primary focus for this research emphasized the lift and drag components. While the lift measurement is straightforward the effective drag is related to the magnitude of the momentum coefficient and is complicated by the unknowns related to the Coanda jet penetration angle. The complexities of the drag measurements can become negative due to the thrust component of the jet. To ensure accurate balance measurements, the balance 
was statically calibrated with and without the influence of the air delivery system shown in figure 12.

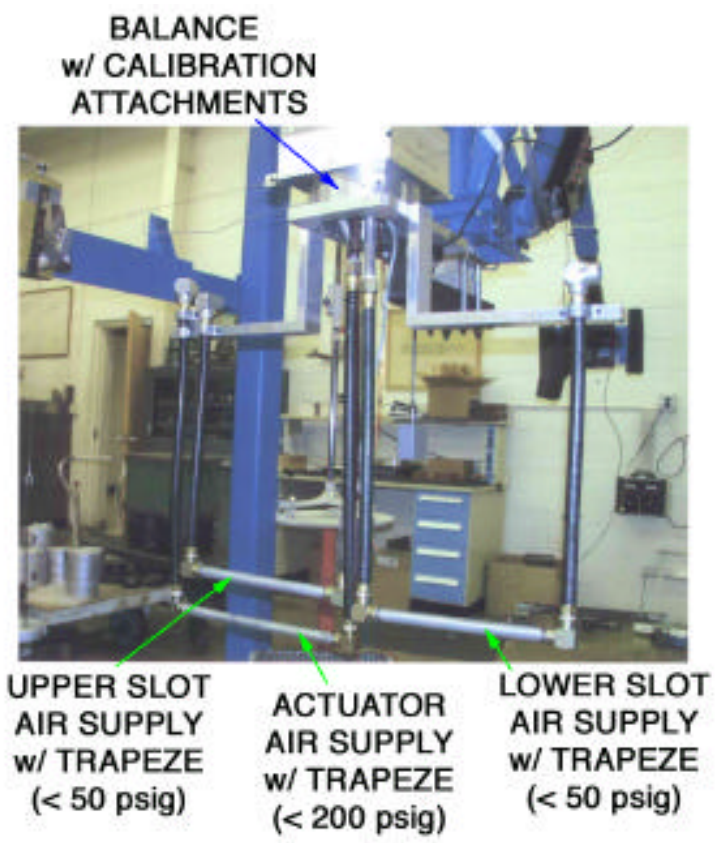

Figure 12. Photograph of the GACC 5component strain gage balance calibration setup.

Calibration results ${ }^{3}$ are applied to a $6 \mathrm{x} \quad 21$ calibration matrix that account for the linear interactions $\left(1^{\text {st }}\right.$ order $)$ and the second-degree nonlinear interactions of the balance. ${ }^{5}$ The calibration coefficients were integrated into the BART data system to provide real time force and moment information. The load limits for the GACC balance are shown in Table 1 .

\begin{tabular}{|c|c|c|}
\hline Component & Load & $\begin{array}{c}\text { Accuracy } \\
\% \text { F.S. }\end{array}$ \\
\hline Normal force & $100 \mathrm{lb}$ & 0.04 \\
\hline Axial Force & $5 \mathrm{lb}$ & 0.39 \\
\hline Pitch & $400 \mathrm{in}-\mathrm{lb}$ & 0.12 \\
\hline Roll & $1200 \mathrm{in}-\mathrm{lb}$ & 0.07 \\
\hline Yaw & 40 in-lb & 1.64 \\
\hline
\end{tabular}

Table 1. GACC balance load limits

The beam for the drag measurement is small, making the balance fragile, and yielding a low resonance frequency $(12.7 \mathrm{~Hz})$ that is easy to excite. This was unavoidable for the drag resolution required.

\section{Pressure Measurement System}

Instrumentation of the GACC model proved to be a major challenge, due to the unsteady measurement of pressure, and the physical size limitations of the model, particularly at the trailing edge. 2-D CFD studies ${ }^{2}$ were used to determine the size and location of the GACC pressure instrumentation. Using the measured surface pressure profiles to obtain model lift, drag, and pitching moment complement the balance data. The large pressure gradients at the trailing edge near the Coanda jet suggested that a high concentration of trailing edge pressure measurements is required, figure 13.

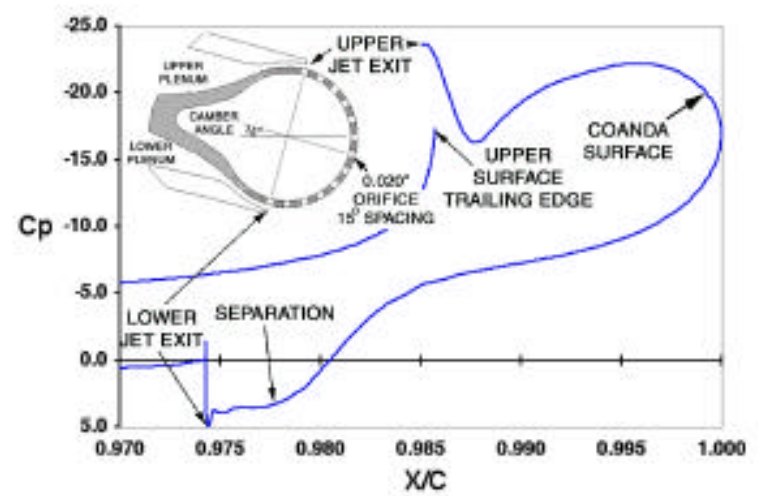

Figure 13 Example of CFD trailing edge steady pressure gradients $(\mathrm{C} \mu \mathbf{0 . 1 6})$

Packaging limitations prevented locating all of the pressure instrumentation along a single span location. The instrumentation was placed in a 3" instrumentation spar located at the model mid-span (figure 14).

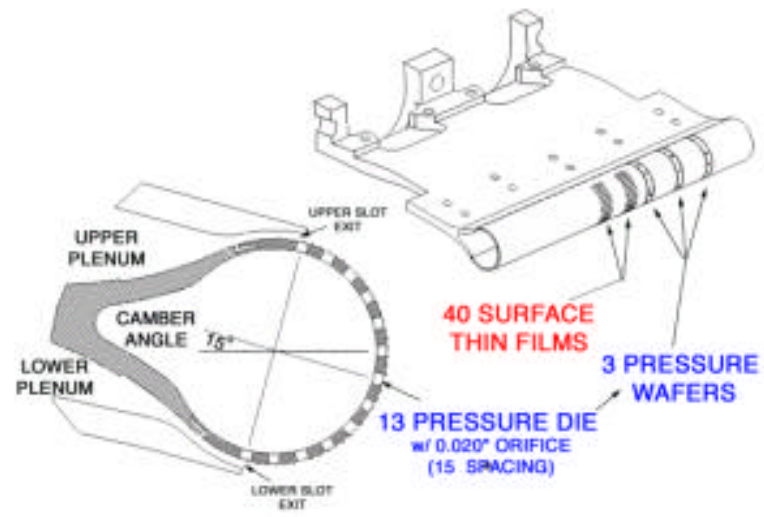

Figure 14 Trailing edge dynamic measurements

Within the $3 / 8$ " trailing edge diameter, there are thirteen unsteady pressure measurements located around the $180^{\circ}$ Coanda surface. Due to size constraints, they were staggered on three wafers with minimal span wise separation. The measurements are made with 0.020" x 0.020" piezoresistive microelectronic pressure die mounted 
in close proximity to the surface. The 5 psig pressure die coupled with the 0.020 " orifice has a frequency response greater than $25 \mathrm{kHz}$. The internal trailing edge cavity pressure was measured with an independent 15 psia pressure transducer. The combination of these measurements assured accurate mean and fluctuating pressures magnitudes could be obtained over the entire Coanda surface.

To complement the trailing edge pressure measurements and improve the spatial resolution, 40 thin films were located around the same $180^{\circ}$ arc. The thin film sensors were not calibrated but used to detect time dependent flow separation. Providing the access for wiring leads to each of these sensors proved to be a challenge. Using a flexible printed circuit bonded around the length of the aft trailing edge diameter solved this problem. This instrumented sheet became the Coanda surface.

In addition to the unsteady pressure measurements, there are an additional 50 static pressure locations on the external airfoil surface, with a high density at the leading edge (figure 15). These pressure orifices were staggered on two closely spaced chordwise locations. Temperature and static pressure are also measured within each air plenum. All of the instrumentation work, including the packaging of the microelectronic pressure sensors, was performed within the LaRC Fabrication Division.

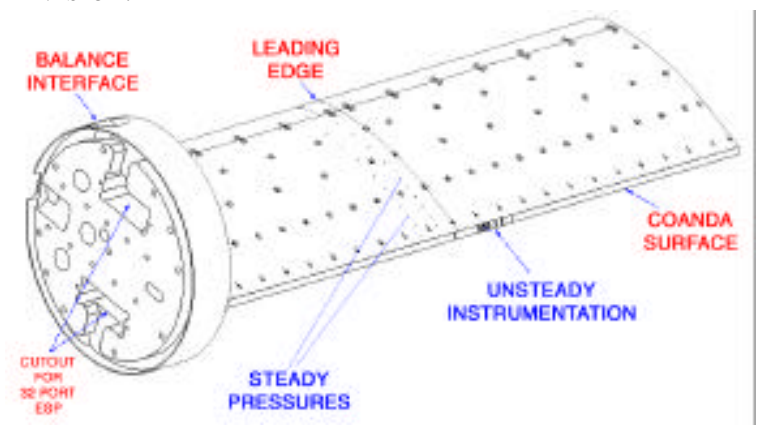

Figure 15 Steady pressure locations

\section{Model Performance}

\section{$\underline{\text { RESULTS }}$}

The GACC model was initially tested in the BART low speed tunnel in November, 2001January, 2002. In general, the model performed very well. The pulsed pneumatic system performed as anticipated. Of course, there were some areas for improvement. The trailing edge adjustment system using opposing screws worked adequately for setting the slot width. With a desired width of between .005-.020", it is evident that a very small deviation in slot width can have a considerable percentage error. This could lead to inaccurate flow parameter calculations and unwanted threedimensional effects. The slot was set in-situ with a feeler gauge tool, which was easy to use but of questionable repeatability. A precision depth gauge measurement system is being fabricated for future tests. Small threaded hex key fasteners were used for the opposing screw adjustment system and to hold the model skins in place. The only significant problem was that the small size of the screws led to occasional rounding out of the hex key slot. Frequent fastener replacement helped this matter greatly.

Pressure drops through the steady state region of the model were an issue. The internal flow paths of this model were mainly driven by actuator requirements. Very little can be done to significantly improve the flow inside the model. Outside of the model, there were several sharp $90^{\circ}$ bends that will be replaced by more gentle sweeps. Pressure drop within the unsteady, high pressure region was not an issue.

The unsteady instrumentation presented several problems. The piezorestrictive pressure module developed a leak while being mounted to the model. At this point, repair was not possible. It made for questionable calibration, and generally decreased the confidence in their results. Better mounting procedures are being explored for future tests. The single aft plenum unsteady pressure measurement probe failed early in testing. This created uncertainty in the pressure just before the trailing edge slot. The thin film gauges are extremely fragile and are in an exposed area. The balance also presented some test challenges. Being soft in the drag direction, the low resonance frequency was easily excited during testing. When coupled with the cantilevered model, the balance had a natural frequency around $12.7 \mathrm{~Hz}$. It often exceeded load limits due to vibration. The allowable test loads were increased (with reduction in safety factor) and this helped somewhat. This unwanted vibration limited the model test matrix to a dynamic pressure of 10 psf.

\section{Data Acquisition System}

The data acquisition system shown in the block diagram in figure 16 is broken into two separate systems that are based on the acquisition speed. The high-speed system utilizes four 8Channel, 16-bit, 196 kHZ simultaneous digitizers that have on-board, phase matched signal conditioning. This system was used to capture the transients and time varying data associated with the trailing edge pressures, surface thin films, and balance subsystems. 
BART's low-speed data system is based on a 64 channel, 16-bit resolution digitizer that has an aggregate sample rate of $100 \mathrm{k}$ samples per second. The low speed system was used to acquire the tunnel conditions and the mean voltages associated with the balance, trailing edge pressures, and surface thin films. Each subsystem was triggered with a trigger signal from the actuator drive system. Nominally the high-speed system was set to 51,200 $\mathrm{Sa} / \mathrm{sec}$ and the low speed system was set to 50 $\mathrm{Sa} / \mathrm{sec}$. Each system acquired 8 seconds of data and is related to a system bandwidth of $1<\mathrm{Hz}<25,600$. This corresponds to $50 \mathrm{Mbytes}$ of data for each data point, creating a data management and storage problem for the PC based computer systems. A custom LabView software package that was developed for this test and was optimized for acquisition speed, automation, and real time system calibration.

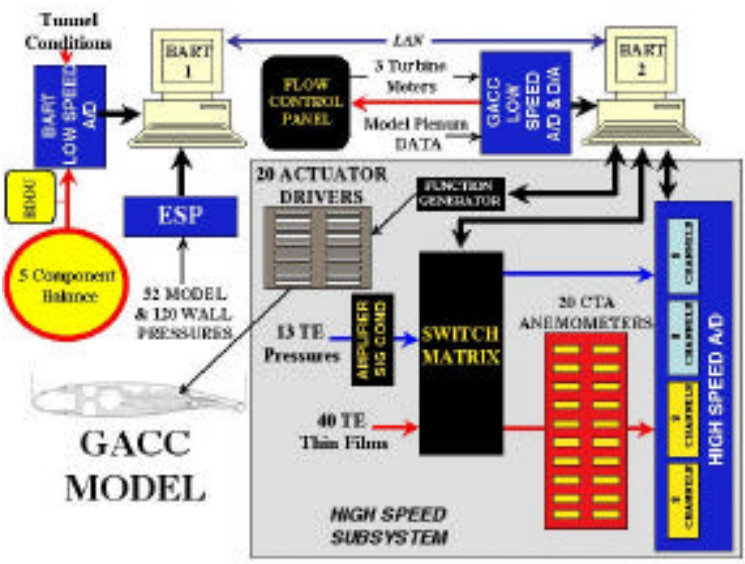

Figure 16 Block diagram of the BART/GACC data acquisition

The 13 trailing edge fluctuating pressure data and 40 surface thin film data were input into a switch matrix that interfaced to the 32 channel high speed A/D system. The thin films were switched in blocks of 20 films per data point. This required sampling a given condition twice to achieve a full scan of the Coanda surface. Film resistances were matched to achieve nominal overheats of 1.2 as a given anemometer was switched from one film to film.

\section{Test Results}

To capture the details of the physics associated with circulation controlled concepts, a flow visualization experiment was used to highlight the global effects of circulation control. Figure 17 illustrates the characteristic flow turning associated with circulation control airfoils. The flow visualization experiment also highlighted several important features of the GACC model, including
- 3-D slot flow can be generated without appropriate internal flow conditioning and result in inefficient flow turning,

- velocity ratios near 1 are the most efficient for the dual blowing cruise conditions, and

- flow at tunnel walls can become separated with the high degree of turning associated with circulation control airfoils.

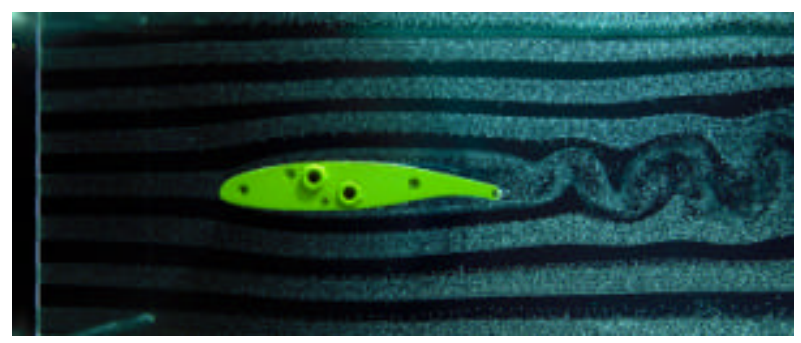

a) No Blowing

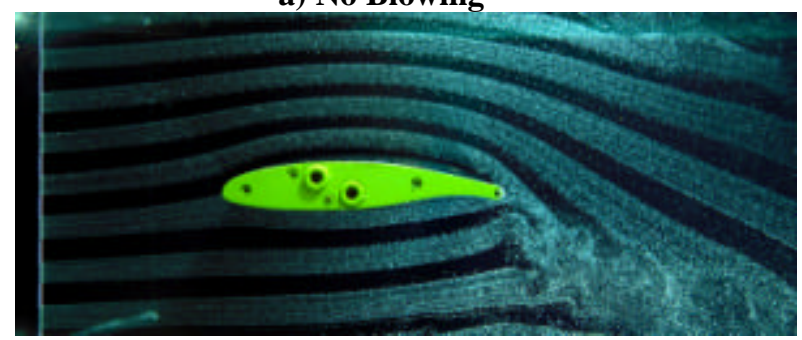

b) Upper surface blowing

Figure 17 Water tunnel model with hydrogen bubble enhance flow visualization.

Establishing the baseline performance of the GACC airfoil was focused on lift performance and the required added mass requirements related to circulation control. The baseline lift results are shown in figure 18. The GACC experimental lift results evaluated at an angle of attack of zero will provide lift augmentation, $\Delta \mathrm{C}_{\mathrm{L}} / \Delta \mathrm{C}_{\mu}=50$.

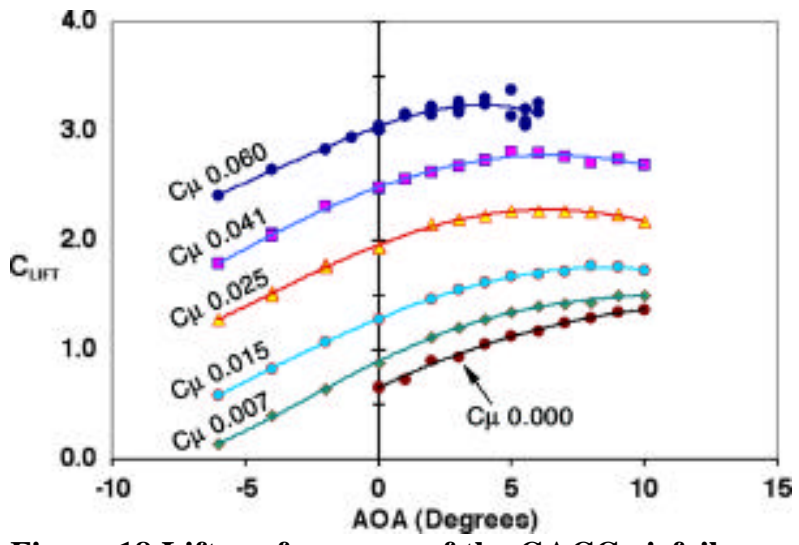

Figure 18 Lift performance of the GACC airfoil 
The minimum drag associated with the dual blowing cruise configuration is shown in figure 19. A $40 \%$ drag reduction compared to the un-blown baseline configuration is realized at a velocity ratio $(\mathrm{Ujet} / \mathrm{Uo})$ of 1.2. Blowing too hard results in an increase in the drag.

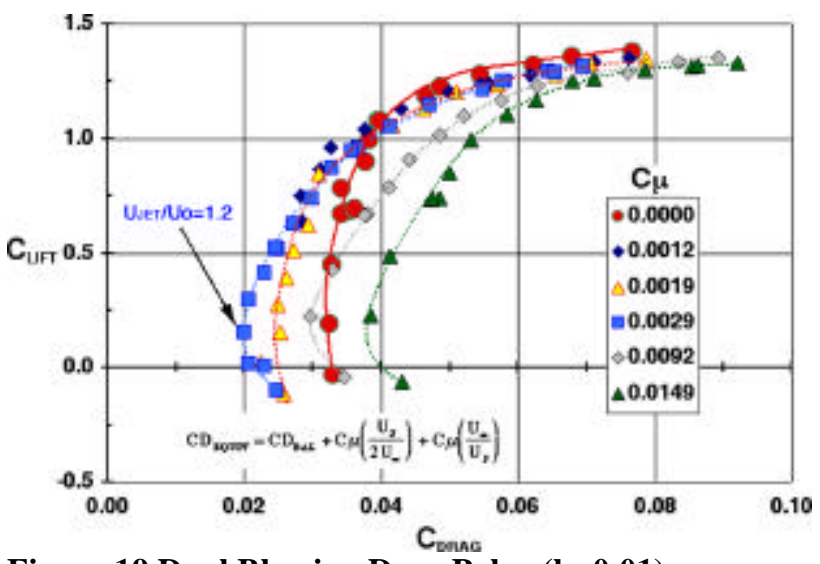

Figure 19 Dual Blowing Drag Polar (h: 0.01)

The pulsed circulation control is characterized by the ability of the pulsed jet to propagate around the Coanda surface. Figure 20 shows the jet perturbation decaying along the surface. The overall result of the pulsed system is to reduce the mass flow requirements for a given lift as shown in figure 21 . A $50 \%$ reduction in the mass flow was obtained at a $20 \%$ duty cycle. For more details that describe the GACC performance see reference 2 .

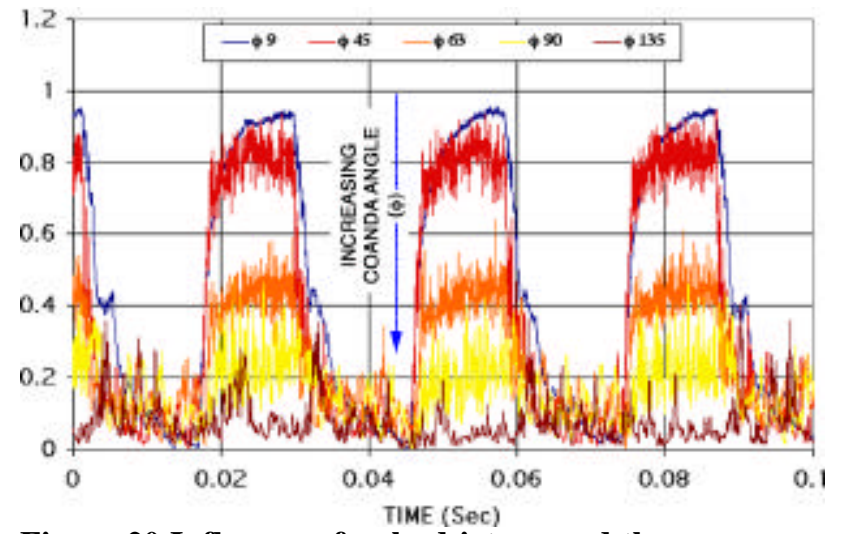

Figure 20 Influence of pulsed jet around the Coanda trailing edge surface $(35 \mathrm{~Hz}, 50 \%$ duty cycle)

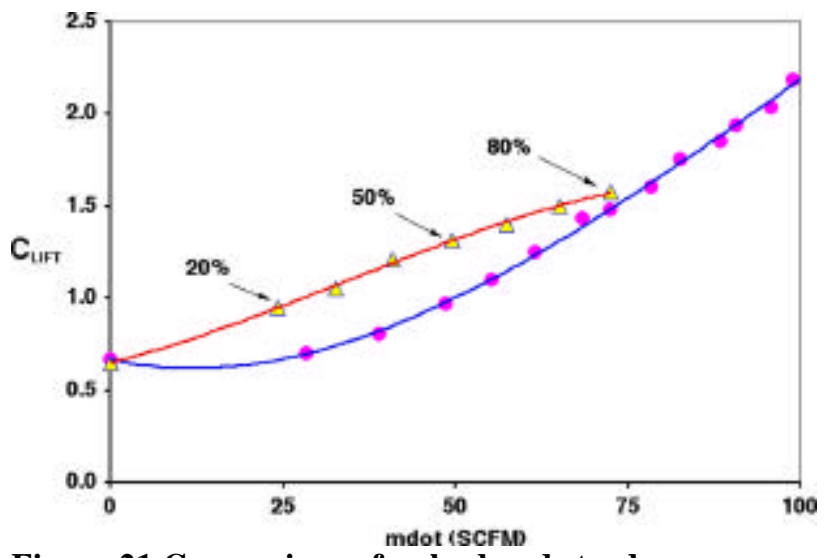

Figure 21 Comparison of pulsed and steady circulation control, (Frequency $35 \mathrm{~Hz}$ w/ varying duty cycle).

\section{CONCLUSIONS}

This model has proven to be a versatile test bed for research into unsteady circulation control and was successful in accomplishing the major test goals. A baseline was established for steady circulation control for this type of airfoil. The GACC airfoil exceeded the target $\mathrm{G}$ of 3 . The pulsed pneumatic actuation system demonstrated a mass flow reduction of 50\% compared to the steady flow for similar lift conditions. A maximum drag reduction of about $40 \%$ was shown for dual steady blowing compared to no blowing for this configuration. The rapid diffuser successfully performed its function of rapidly expanding the actuator jet into a flat sheet of air. The diffuser development approach using Stereolithography worked well. The diffuser was optimized using the as built item so that manufacturing tolerances at this small scale were not a factor. There were also several issues identified for improvement in future tests. The actuator authority is very good, but there is still some attenuation to the pulsed signal due to the design of the model. Slot height is critical to accurate performance measurement and was not adequately controlled. Very small dimensional errors make significant impact to flow area. Due to the resolution required of the force balance, dynamics were difficult to manage and limited the test matrix.

\section{FUTURE DIRECTION}

There are several items that have been identified for future research. There were some issues with the first wind tunnel entry that are currently being addressed. Efforts are being made to minimize balance dynamics. A precision slot height 
measurement system is being built to improve trailing gap setting. The trailing edge dynamic pressure measurement has been redesigned to improve reliability. Another issue for investigation is improvement in actuator authority. This may be accomplished by reduction in plenum volume downstream of the rapid diffuser. Improvements in pneumatic actuator performance are also being addressed. Trailing edge shape optimization is being explored. With this model, actuators are independently controlled. Three dimensional flow effects will be studied by time varying the actuator control signals. Performance of this model at higher test speed will also be explored.

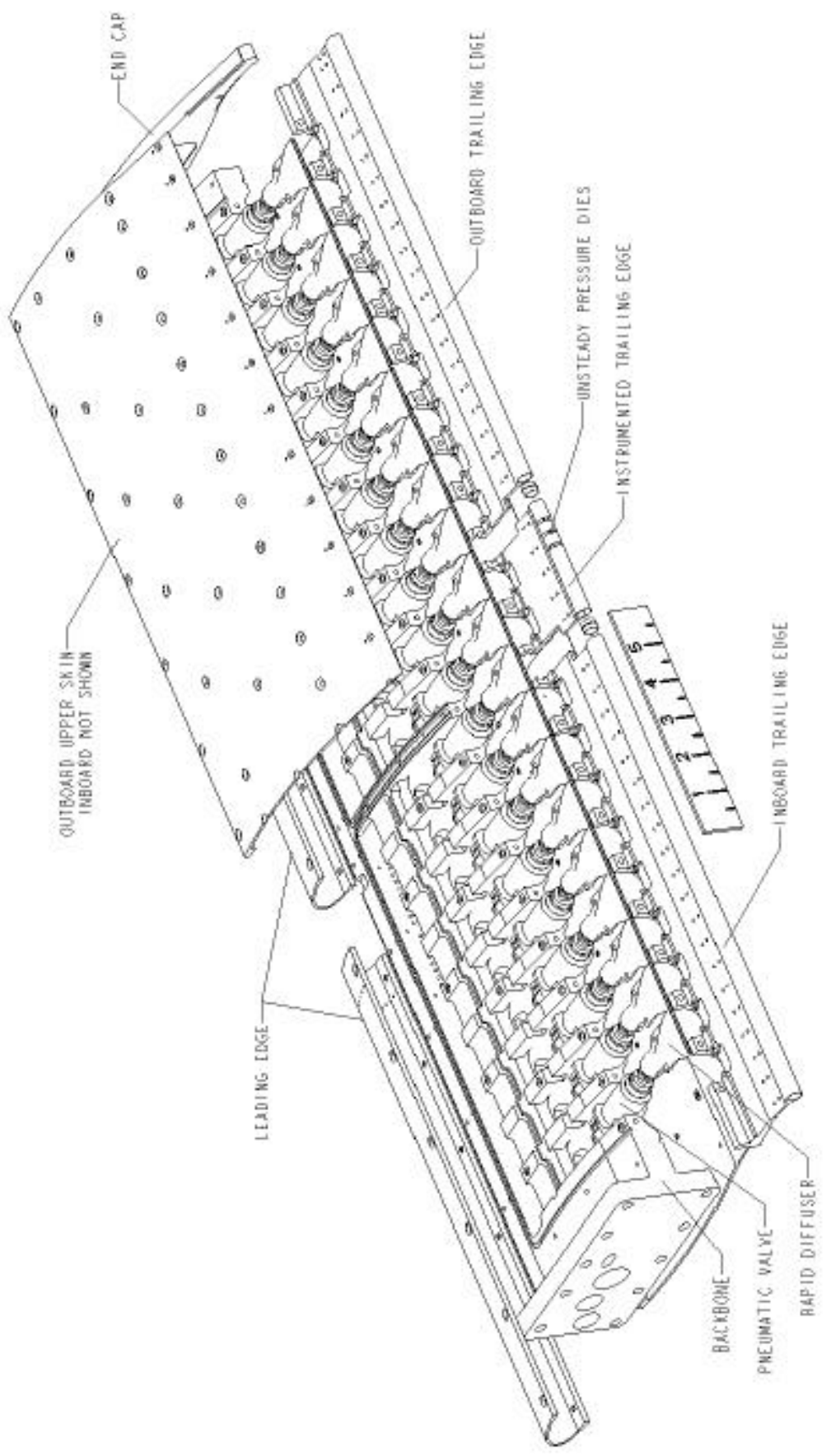

\section{Appendix A Detail of GACC Model}




\section{$\underline{\text { References }}$}

${ }^{1}$ Schlichting, H., "Boundary Layer Theory", page $750-751,2^{\text {nd }}$ Edition, 1979

2 Jones, G.S., Viken, S.A., Washburn, A.E., Jenkins, L.N., Cagle, C.M., "An Active Flow Circulation Controlled Flap Concept for General Aviation Aircraft Applications," AIAA 3157, June 2003

${ }^{3}$ McQuithy, B., Patel, N., "NASA LaRC - GACC Calibration Report", October, 2002

${ }^{4}$ Preller, R.F., Rose, O.J., "Langley Wind Tunnel Force Reduction Program,” NASA CR-165650, November 1980

${ }^{5}$ Smith, D.L., "An Efficient Algorithm using Matrix Methods to Solve Wind Tunnel Force-Balance Equations," NASA-TN-D-6860, August 1972 